\title{
INTOXICAÇÃO POR DIETILENOGLICOL: UM ESTUDO RETROSPECTIVO MUNDIAL DE 1937 AO CASO DA CERVEJARIA DE MINAS GERAIS - BRASIL EM 2020
}

\author{
Clara Maria Diniz Lima \\ Centro Universitário de Belo Horizonte, Belo Horizonte, MG, Brasil \\ Lauren Braga* \\ Centro Universitário de Belo Horizonte, Belo Horizonte, MG, Brasil \\ Claiton Pires Ventura \\ Instituto de Criminalística, Policia Civil do Estado de Minas Gerais, Belo Horizonte, MG, Brasil \\ Cristiano Otávio Luciano Goulart \\ Instituto Médico Legal André Roquette, Polícia Civil do Estado de Minas Gerais, Belo Horizonte, MG, Brasil
}

\section{DIETHYLENE GLYCOL POISONING: A 1937 WORLD RETROSPECTIVE STUDY - FROM 1937 TO THE 2020 BREWERY CASE IN MINAS GERAIS, BRAZIL}

\section{RESUMO}

Dietilenoglicol é uma substância química totalmente incolor, inodora e de sabor adocicado e é utilizada como intermediário químico nas indústrias, principalmente como solvente ou anticongelante. 0 dietilenoglicol foi apontado como agente responsável por intoxicações em massa desde os anos de 1930, em cerca de seis países. Quando usado erroneamente, pode resultar em efeitos adversos significativos à saúde, incluindo insuficiência renal e letalidade. As intoxicações não são comuns, porém, são notórias por ocorrerem de forma epidêmica e com alta mortalidade. Geralmente os casos acontecem pela adulteração, falsificação e substituição de substâncias não tóxicas pelo dietilenoglicol. Apesar do efeito inebriante, a substância é praticamente atóxica, sendo o grande problema a sua biotransformação, pois esta dá origem a metabólitos de elevada toxicidade, como o ácido diglicólico. 0 primeiro relato de intoxicação em massa conhecido ocorreu no ano de 1937 nos Estados Unidos da América (EUA). Este trágico evento gerou impacto nacional e levou o Congresso Norte-americano a aprovar a criação do Food and Drug Administration, agência federal do Departamento de Saúde e Serviços Humanos nos EUA. No presente estudo, foram descritas as diversas intoxicações que ocorreram ao longo dos últimos oitenta anos, com ênfase nos casos que ocorreram em Minas Gerais - Brasil no final do ano de 2019 e início de 2020.

PALAVRAS-CHAVE: Dietilenoglicol. Envenenamento por dietilenoglicol. Ácido diglicólico.

\section{ABSTRACT}

Diethylene glycol (DEG) glycol is a completely colorless, odorless and sweet-tasting chemical substance, used as a chemical intermediary in industries, mainly as a solvent or antifreeze. Diethylene glycol has been identified as an agent responsible for massive poisoning since the thirties, in about six countries. When misused, it can result in proven adverse related health effects, including kidney failure and lethality. Poisonings with DEG are not an ordinary happening, however, they are notorious for occurring in an epidemic way and with high mortality results. Usually, these events occur due to adulteration, falsification and replacement of non-toxic substances by diethylene glycol. Despite the intoxicating effect, this substance is practically non-toxic, the major problem being its biotransformation, as it gives rise to highly toxic metabolites, such a diglycolic acid. The first massive poisoning occurred in 1937 in the United States, and this tragic event had a national impact and led the North American Congress to approve the creation of the Food and Drug Administration, a federal agency of the Department of Health and Human Services in the United States. In this present study, there were described several intoxications that occurred over the last eighty years, especially the cases that occurred in Minas Gerais - Brazil, from late 2019 until the beginning of 2020.

KEYWORDS: Diethylene glycol. Diethylene glycol poisoning. Diglycolic acid. 


\section{INTRODUÇÃo}

O dietilenoglicol (DEG) é uma substância química transparente, incolor, inodora, de sabor adocicado e completamente solúvel em água' ${ }^{1}$ O DEG é um produto químico usado principalmente como solvente ou anticongelante.

Segundo Fink $(2003)^{2}$, os anticongelantes são compostos químicos que são adicionados a fluidos à base de água para reduzir o ponto de congelamento da mistura. Existem várias aplicações em diversos setores industriais, como nos meios automobilísticos, químicos e no setor petrolífero. Além disso, geralmente são usados em equipamentos mecânicos no período de inverno para evitar o congelamento das soluções aquosas. Dentre os anticongelantes mais utilizados temos as salmouras com cloreto de cálcio, álcoois (metanol, etanol e isopropanol), glicerol e glicóis.

Os sais, como o cloreto de cálcio, são de fácil obtenção, porém, são pouco utilizados devido ao grande poder de corrosão. Já a utilização dos álcoois não traz o problema da corrosão, entretanto, estes são caros e podem ser tóxicos ${ }^{3}$. Os álcoois utilizados como anticongelantes são: etanol, metanol, etilenoglicol, propilenoglicol e glicerol, e são divididos em voláteis e não voláteis. Os voláteis podem causar problemas de combustão, enquanto os álcoois glicóis (etilenoglicol e propilenoglicol) não são voláteis e funcionam bem como anticongelantes ${ }^{3}$. Dentre os glicóis, existem o monoetilenoglicol, DEG e o trietilenoglicol. Todos apresentam a mesma função. A principal diferença entre esses solventes é o nível de toxicidade, sendo o DEG mais tóxico para os seres humanos. Além disso, Fink (2003) $)^{2}$ indicou a aplicação do etilenoglicol como anticongelante por causa de sua eficiência térmica, porém, este álcool tem o uso limitado devido à sua toxicidade.

O DEG tem sido apontado como agente responsável por causar intoxicação "em massa" em cerca de seis países nos últimos oitenta anos. 0 mau uso pode resultar em exposição humana ao agente nocivo e a ingestão oral de DEG pode ocasionar efeitos adversos significativos à saúde, incluindo insuficiência renal e letalidade. A dose considerada letal para humanos é de 0,5 a $5 \mathrm{~g} \mathrm{~kg}^{-1}$, podendo causar: depressão nervosa, lesões nos rins e fígado, anúria e irritação no trato gastrointestinal. Os sintomas variam entre náuseas, vômitos e diarreia, além da Injúria Renal Aguda (IRA), devido à degeneração tubular cortical, lesão proximal e necrose tubular ${ }^{4}$. São resultantes do metabolismo do DEG diferentes metabólitos, entre eles: 0 ácido 2-hidroxietoxiacético (2-HEAA) e o ácido diglicólico (ADG). Desses, o ácido diglicólico é o responsável pela maior toxicidade do DEG, resultando na necrose das células dos túbulos proximais, gerando ausência celular de ATP que antecede a apoptose ${ }^{5}$.

A intoxicação por DEG não é uma intoxicação comum, porém, costuma ser notória devido à tendência de ocorrer de forma epidêmica e com alta letalidade. Normalmente os casos documentados aconteceram devido à substituição da glicerina e do propilenoglicol ${ }^{6}$. Geralmente acontecem em países em desenvolvimento, onde o controle de qualidade é considerado abaixo da média, além da dificuldade de acesso aos tratamentos médicos intensivos e à carência de equipamentos analíticos ${ }^{4}$. Evidências sugerem que os principais motivos que levam à intoxicação em massa por DEG são: 1) intenção de enganar pessoas ou organizações dentro do processo de fabricação, visando o ganho financeiro e 2) falha na adesão de "Good Manufacturing Practices" (GMP) e controle de qualidade inadequado ${ }^{7}$.

Sabendo da importância da identificação imediata da intoxicação por DEG, o presente trabalho objetivou analisar as evidências sobre a intoxicação por DEG, resumir os principais aspectos da intoxicação, incluindo epidemiologia, toxicocinética, toxicodinâmica, diagnóstico e possíveis tratamentos, além de apresentar casos de intoxicação por DEG nos últimos 80 anos revelando, assim, as principais formas de intoxicação pela substância e os efeitos adversos significativos à saúde.

\section{METODOLOGIA}

Trata-se de uma revisão de literatura integrativa, cujos artigos foram pesquisados em base de dados como PubMED, Biblioteca Virtual em Saúde (BVS) e Periódicos da Capes (Coordenação de Aperfeiçoamento de Pessoal de Nível Superior). Para a pesquisa foram utilizados os descritores encontrados no Medical Subject Heading (MeSH): diethylene glycol, diethylene glycol poisoning e diglycolic acid. Além disso, foram consultadas notas técnicas e orientações não indexadas de condutas médicas para o caso de intoxicação com DEG. Os critérios de inclusão foram artigos originais publicados em inglês ou português entre os anos de 2000 a 2020. Além disso, foi utilizado um artigo do ano de 1972, publicado pelo jornal acadêmico "South African Medical Journal", um artigo do ano de 1987, publicado pelo "American College of Physicians" e um artigo de 1998, publicado por "The Journal of the American Medical Association" (JAMA), devido ao fato de serem as primeiras publicações relacionadas às intoxicações pelo DEG. Os critérios de exclusão foram artigos em duplicata e artigos que não eram relevantes de acordo com o tema proposto.

\section{RESULTADOS}

A busca de artigos nas bases de dados, previamente citadas, resultou em 1.345 trabalhos publicados. Após a aplicação dos critérios de exclusão, foram selecionados 26 artigos, conforme tabela 1 a seguir. 
Tabela 1 - Relação de descritores e artigos encontrados nas bases de dados PubMED, Biblioteca Virtual em Saúde (BVS) e Periódicos da Capes, entre os anos de 2000 a 2020.

\begin{tabular}{cccc}
\hline Descritores & Base de Dados & Artigos Encontrados & Artigos Selecionados \\
\hline Diethylene glycol & PUBMED & 760 & 6 \\
Diethylene glycol poisoning & PUBMED & 79 & 5 \\
& BVS & 75 & 4 \\
& CAPES & 363 & 5 \\
Diglycolic acid & PUBMED & 11 & 2 \\
& CAPES & 56 & 3 \\
\hline
\end{tabular}

A primeira intoxicação em massa por DEG aconteceu em 1937 nos Estados Unidos. A sulfanilamida é um medicamento usado para tratar infecções estreptocócicas e, por muitos anos, foi utilizada na forma de comprimidos e em pó. Na tentativa de usá-lo na forma líquida, foi testada a dissolução em DEG e esta não apresentou alteração quanto à cor, odor e sabor. Na época não eram realizados testes quanto à toxicidade. Dessa forma, os lotes de sulfanilamida antibacteriana contaminados foram distribuídos. Cerca de 350 pacientes foram intoxicados e 105 pessoas morreram 8 .

Em 1969, na África do Sul, sete crianças apresentaram insuficiência renal e morreram após a ingestão de um sedativo de venda livre (Pronap®, Plaxin®). Estudos apontaram que em sua composição houve substituição indevida do propilenoglicol pelo DEG $^{9}$. Na Índia, em 1973, quatorze crianças morreram após ingerirem medicamento contaminado com DEG.

Em 1985, na Espanha, cinco pacientes de uma unidade de tratamento de queimaduras apresentaram insuficiência renal e morreram. Todos os pacientes haviam sido tratados com sulfadiazina de prata tópica e a pomada estava contaminada com 6,2 a $7,1 \mathrm{~g} \mathrm{~kg}^{-1}$ de DEG. Apesar de o DEG ser pouco absorvido pela pele, ocorreu toxicidade sistêmica devido à combinação de pele danificada e repetidas aplicações do produto ${ }^{10}$.

$\mathrm{Na}$ Índia, em 1986, 21 pacientes morreram por falha renal após administração de glicerina contaminada por DEG. Na década de 1990, na Nigéria, cerca de 47 crianças morreram após a administração de acetaminofeno, quando, também, foi apontada a substituição indevida do propilenoglicol por DEG. Na mesma época, houve uma intoxicação semelhante em Bangladesh onde cerca de 236 crianças morreram após o uso desse analgésico ${ }^{11}$.

$\mathrm{Na}$ Argentina, em 1992, estudos apontaram intoxicação em massa devido ao uso de xarope de própolis contaminado. 0 DEG foi o agente intoxicante e causou acidose metabólica, anúria, insuficiência renal e morte em 15 das 29 vítimas estudadas. Neste caso, o xarope de própolis foi analisado por meio de espectroscopia por ressonância magnética nuclear (RMN) e quantificado por cromatografia gasosa com deteç̧ão por ionização de chama. Amostras de sangue e vísceras também foram analisadas qualitativa e quantitativamente ${ }^{12}$.

A intoxicação pelo DEG no Haiti ocorreu em meados do ano de 1996, sendo o xarope de acetaminofeno contaminado com concentração média de 14,4\% de DEG. De acordo com os relatos, 109 crianças apresentaram sintoma de insuficiência renal aguda. Oitenta e sete delas ficaram no Haiti para tratamento. Oitenta e cinco evoluíram para morte. Os onze pacientes restantes foram para os EUA em busca de tratamento em uma unidade de terapia intensiva, três deles morreram ${ }^{13}$. Em 1998, a Índia enfrentou uma nova intoxicação em massa devido a um medicamento contaminado com DEG. Desta vez, 33 morreram após a ingestão de um expectorante e oito morreram após a utilização de acetaminofeno. Ambos os medicamentos estavam contaminados por DEG. Os medicamentos suspeitos foram testados por meio de métodos colorimétricos e espectrofotometria ${ }^{14}$.

Em 2006, na China, 64 pacientes foram internados por apresentarem doença hepática moderada ou grave. Doze deles morreram, sendo a causa principal a ingestão de xaropes ou uso de soluções dérmicas contaminados com DEG. A concentração de DEG na Armillarisin-A foi determinada por espectrofotometria $^{15}$. Segundo PENG (2009) ${ }^{16}$, a dose total de exposição por dia foi de 3 a $6 \mathrm{~mL}$ de uma mistura de $30 \%$ (v/v). Em setembro de 2006, um médico do Panamá estranhou o surto de insuficiência renal aguda geralmente acompanhada de disfunção neurológica grave $^{17}$. Investigações realizadas para identificar a origem desse surto levantaram suspeitas quanto à intoxicação por DEG. Entretanto, somente após dois meses fizeram testes confirmatórios e identificaram o DEG na composição de um xarope para tosse por meio dos testes de cromatografia gasosa acoplada à espectrometria de massa (CG-EM) com ionização por impacto por elétrons e com ionização química por metano ${ }^{18}$. Além disso, em 2007 foi encontrado DEG em creme dental de diversas marcas em cerca de 30 países. Porém, nenhum caso de adoecimento parece estar relacionado ao uso deste produto de higiene bucal ${ }^{19}$.

No ano de 2008, na Nigéria, ocorreu uma nova intoxicação devido um xarope para aliviar a dor de dente chamado "My Pickin" (paracetamol com cloridrato de difenidramina). Cinquenta e sete das 59 crianças que foram internadas morreram e duas crianças que receberam etanol intravenoso (antídoto) também evoluíram para óbito. Elas apresentavam como sintomas: nefropatia tóxica, sepse, gastroenterite, glomerulonefrite, síndrome hemolítica urêmica, doença renal aguda ou crônica, além da intussuscepção. 
Segundo AKUSE e colaboradores (2012) ${ }^{20}$, a concentração de DEG era de 17 a $21 \%$. A técnica utilizada para deteç̧ão do DEG foi a CG-EM. Foram recolhidas, aproximadamente, $51 \%$ das 15.000 garrafas produzidas entre agosto e outubro de 2008 , sendo enviadas ao Centro de Química Forense da FDA (Food and Drug Administration) para análise. Como resultado, obtiveram 17 a $21 \%$ de DEG em seis dos sete medicamentos residuais (garrafas recuperadas em residências) e em quatro lotes de garrafas recuperadas durante a retirada do produto da comercialização $0^{20}$.

No primeiro mês do ano de 2020, aconteceu o quarto envenenamento em massa por glicol na Índia: doze crianças morreram de falência renal após ingerirem xarope para tosse contaminado com DEG ${ }^{21}$.

Além dessas contaminações de medicamentos, acidentais ou não, já foram encontrados dois casos de contaminação de bebidas alcoólicas por DEG. 0 mais importante aconteceu na Áustria em 1985, quando um vinho de baixa qualidade foi fraudado, e na intenção de aumentar a sensação de corpo e dulçor (características sensoriais de vinhos nobres), foi adicionado DEG. Apenas um caso de falência renal aguda foi relatado. Entretanto, podem ter ocorrido mais casos sem que a correlação com o vinho tenha sido feita. Em 1986, vinhos italianos também apresentaram contaminações por monoetilenoglicol e DEG. Porém, investigações foram feitas e chegaram à conclusão que se tratava de uma intoxicação acidental, pois diferentemente dos vinhos produzidos na Áustria, os vinhos italianos têm alto valor agregado e passam por uma denominação de origem, uma forma de garantir que os vinhos de uma mesma região tenham características similares ${ }^{19}$.

Um último evento de intoxicação pelo DEG aconteceu no Brasil quando surgiram alguns casos no final de 2019 e início de 2020. No dia 30 de dezembro de 2019, a Secretaria Municipal de Saúde de Belo Horizonte (SMSA-BH), juntamente da Secretaria de Estado de Saúde de Minas Gerais (SES-MG), foi notificada quanto a um caso de insuficiência renal aguda com alterações neurológicas em um paciente internado em hospital privado de Belo Horizonte. Um dia após este evento, foi notificado um segundo caso em Juiz de Fora, uma cidade localizada na Zona da Mata Mineira. Os casos de intoxicação evoluíram rápido em Minas Gerais contando com cerca de trinta e um casos confirmados. Todos os pacientes apresentavam sintomas semelhantes: sintomas gastrointestinais agudos, insuficiência renal e alterações neurológicas. 0 primeiro óbito foi confirmado em 8 de janeiro de 2020. Diante disso, solicitou-se à Fundação Ezequiel Dias de Minas Gerais (FUNED/MG) que realizasse exames laborato- riais para que fossem eliminadas as suspeitas de arboviroses, febres hemorrágicas, infecções bacterianas, infecções fúngicas sistêmicas e doenças neuroinvasivas. Adicionalmente às análises realizadas pela FUNED/MG, a Superintendência de Polícia Técnico-Científica da Polícia Civil do Estado de Minas Gerais (SPTC/PCMG) realizou análises toxicológicas em amostras biológicas dos pacientes, por meio de CG-EM, para pesquisa de $D E G$ e/ou $A D G$ no sangue, urina, humor vítreo, líquor, fígado e rim das vítimas. No dia 9 de janeiro, foi confirmada a intoxicação por DEG de dois lotes de cerveja e em 10 de janeiro, foi identificada a presença de DEG em amostras clínicas de dois pacientes. No decorrer das análises, 39 amostras foram examinadas, $e$ em onze delas foram detectadas a presença de ADG.

Após meses de investigação, peritos criminais da PCMG contataram que havia um furo de, aproximadamente, $1,5 \mathrm{~mm}$ em um tanque, que resultou em um vazamento, levando a um extravasamento do líquido anticongelante, o qual entrou em contato com a cerveja, resultando na contaminação da mesma por monoetilenoglicol e DEG, substâncias tóxicas usadas no resfriamento do produto. É importante lembrar que, na indústria alimentícia, é indicado fazer o uso de anticongelante não tóxico, como etanol.

\section{DISCUSSÃO}

\section{Toxicidade do DEG}

Apesar do efeito inebriante, o DEG por si só, é praticamente atóxico. Ele é absorvido rapidamente pelo trato gastrointestinal, distribuído para a corrente sanguínea e, dentro de 30 a 60 minutos, é metabolizado pelo fígado e excretado pelos rins. 0 grande problema está na sua biotransformação, pois dá origem a metabólitos de elevada toxicidade ${ }^{4}$. Cerca de dois terços do DEG é excretado inalterado na urina. A fração remanescente é metabolizada por meio das diversas reações oxidativas no fígado: primeiro, o DEG é metabolizado em 2-hidroxietoxiacetaldeído pela enzima álcool desidrogenase (ADH); depois, em ácido $2-$ hidroxietoxiacético (2-HEAA) pela enzima aldeído desidrogenase (ALDH), podendo, ainda, ser oxidado em ADG (Sociedade Brasileira de Nefrologia, 2020) $)^{23,24}$

De acordo com a nota técnica publicada pela Secretaria de Estado de Saúde de Minas Gerais, as alterações clínicas esperadas estão apresentadas no quadro 1 abaixo.

Um diagnóstico presuntivo pode ser alcançado por meio 
Quadro 1: Alterações clínicas esperadas em caso de intoxicação exógena por DEG.

\begin{tabular}{|l|l|}
\hline Trato Geniturinário & Oligúria, anúria e dor lombar. \\
\hline Trato gastrointestinal & Náuseas, vômitos, dor abdominal e diarreia. \\
\hline Alterações Oftalmológicas & $\begin{array}{l}\text { Turvação visual, midríase, amaurose e alteraça do campo } \\
\text { visual. }\end{array}$ \\
\hline Alterações Neurológicas & $\begin{array}{l}\text { Ptose palpebral, dificuldade de deglutição, paralisia facial e } \\
\text { crise convulsiva. }\end{array}$ \\
\hline Alterações Respiratórias & $\begin{array}{l}\text { Taquipneia, insuficiência ventilatória após instalação do } \\
\text { quadro neurológico. }\end{array}$ \\
\hline $\begin{array}{l}\text { Alterações } \\
\text { Cardiovasculares }\end{array}$ & Hipertensão arterial. \\
\hline
\end{tabular}

Fonte: Secretaria de Estado de Saúde de Minas Gerais, $2020^{22}$.

da anamnese e exame físico, principalmente em meio a um surto sabidamente atribuído ao envenenamento por DEG. De acordo com orientação do CIATOX-MG e FUNED, deve-se solicitar a dosagem de DEG e avaliação do equilíbrio hidroeletrolítico. O gap osmolar, ou hiato osmolar (HO), pode amparar a detecção de uma provável intoxicação quando está elevado, sendo que a elevação concomitante ou sequencial do gap, ou hiato aniônico $(\mathrm{HA})$, sugere tratar-se de álcool tóxico, sendo transformado em seu metabólito ácido. A osmolalidade sérica pode ser medida por meio do osmômetro pela técnica de depressão do ponto de congelamento, e costuma ficar entre 285 a $290 \mathrm{mOsm} \mathrm{L}^{-1}$, devido ao sódio e íons ${ }^{23}$. O hiato osmolar é aceitável quando apresenta valores entre 10 e 20 mOsm $\mathrm{kg}^{-1} \mathrm{H} 2 \mathrm{O}$. Níveis mais elevados podem indicar acúmulo de substâncias osmoticamente ativas - álcoois, geradores ou não de metabólitos tóxicos. Em caso de intoxicação pelo DEG, valores acima de $50 \mathrm{mOsm} \mathrm{kg}{ }^{-1} \mathrm{H} 2 \mathrm{O}$ podem aparecer, sendo a concentração sanguínea estimada multiplicando o $\mathrm{HO}$ por 1/10 do peso molecular. Como exemplo, um paciente com $\mathrm{HO}$ de 50 mOsm kg-1 H2O, tem sua concentração estimada da ordem de $50 \times(106 / 10)$ ou $530 \mathrm{mg} \mathrm{dL}^{-1}$. Outra variável é o hiato aniônico, que, para interpretação, deve-se conhecer a cloremia aferida pelo método colorimétrico ou por eletrodo seletivo. Também foi recomendado pela Sociedade Brasileira de Nefrologia (SBN), a correção da albuminemia. Existem variações do HA, devido à dependência da inclusão da potassemia, importante nos casos de insuficiência renal aguda. Os valores de referência para o HA são: com eletrodo seletivo para cloro (11 a $17 \mathrm{mEq} \mathrm{L}^{-1}$ ); com método colorimétrico para cloremia (7 a $13 \mathrm{mEq} \mathrm{L}{ }^{-1}$ ). Os valores acima de $24 \mathrm{mEq} \mathrm{L}^{-1}$ são encontrados nos casos de envenenamento por álcoois tóxicos. Entretanto, o HA normal não exclui a possibilidade de intoxicação $0^{23}$.

Um paciente pode apresentar um HA prévio baixo e estar na fase da doença onde o hiato aniônico ainda não se elevou ou já ter sido corrigido pela hemodiálise. Nas primeiras horas de absorção, o hiato osmolar (HO) se eleva, sendo que o hiato aniônico (HA) pode ainda estar normal. À medida que o DEG é biotransformado e seus metabólitos ácidos gerados, o $\mathrm{HO}$ entra em declive enquanto o HA eleva (Sociedade Brasileira de Nefrologia, 2020). Além disso, níveis elevados das enzimas hepáticas, au- mento do nitrogênio da ureia no sangue e aumento nos níveis de creatinina podem ser observados. A acidose metabólica também ocorreu em diversos pacientes e dados histopatológicos dos rins, após o envenenamento fatal pelo DEG, que mostraram edema intersticial e necrose tubular extensa ${ }^{24}$.

De acordo com nota técnica da Sociedade Brasileira de Nefrologia (SBN), é possível obter o diagnóstico da intoxicação por meio da dosagem sérica do DEG. Porém, é um método trabalhoso, caro e inacessivel à maioria dos hospitais e serviços de emergência. Foi visto, no decorrer deste trabalho, que houve dezenas de intoxicações por DEG. Por anos, acreditava-se que a toxicidade da substância era devido ao 2-HEAA, um de seus metabólitos. Entretanto, há estudos que apontam que o DEG exerce sua ação tóxica por meio do ADG. Essas evidências foram demonstradas in vitro e in vivo, tanto em animais experimentais quanto em humanos. Além disso, estudos com animais experimentais apontam que $\mathrm{ADG}$ é mais lentamente excretado, ainda se mostrando detectável mesmo após não ser mais possível a constatação do DEG. Um estudo de caso feito no Panamá demonstrou que a análise de ADG é o parâmetro laboratorial com melhor correlação com os casos de intoxicação, quando comparadas com amostras controle. Por isso, a presença de ADG nas amostras biológicas de paciente é um marcador laboratorial, e tornou-se relevante por ser detectável por tempo maior e por já ter sido empregado com sucesso em casos reais de intoxicação em massa por DEG 8,22,23.

Para análise e pesquisa do ADG nas amostras de sangue e urina das vítimas de Minas Gerais, o Instituto Médico Legal André Roquette (IMLAR) utilizou, como extração, a precipitação de proteínas utilizando como solvente a acetonitrila, e analisou os extratos por Cromatografia Gasosa acoplada à Espectrometria de Massas (CG-EM).

De acordo com o Ministério da Agricultura, Pecuária e Abastecimento (MAPA) ${ }^{19}$, a análise das amostras de cerveja coletadas na própria fábrica, e no comércio, foram realizadas por um procedimento de diluição com etanol, centrifugação e análise por CG-EM. Essa técnica analítica é a mais utilizada e foi considerada referência pela agência americana Food and Drug Administration (FDA) para a determinação dessas substâncias. 


\section{Tratamento}

O tratamento consiste na inibição do metabolismo e eliminação do DEG e seus metabólitos. Algumas medidas iniciais devem ser tomadas, como controle da arritmia, tratamento das convulsões, intubação e ventilação mecânica. Devido ao seu comportamento farmacocinético, e por ser uma substância de primeira ordem, com meia-vida de aproximadamente 4 horas, bastam apenas 16 horas para que 94\% do DEG já tenha sido biotransformado ou eliminado pela urina. Por isso, a descontaminação por meio da êmese induzida deve ser desconsiderada após 2 horas de ingestão. Em relação ao tratamento tardio e prognóstico, uma vez que há disfunção celular que resulta na insuficiência renal aguda e na nefropatia, não existe um tratamento terapêutico ou antídoto capaz de reverter a lesão por imediato. São utilizados tratamentos de suporte em que alguns pacientes demonstram melhora gradual. Entretanto, estes tratamentos podem acarretar sequelas a longo praz $0^{23}$.

\section{Antídotos}

Após a ingestão, a produção dos metabólitos tóxicos se inicia através da ação da enzima álcool desidrogenase (ADH). Sendo assim, a interrupção dessa via é um dos principais tratamentos da intoxicação por $\mathrm{DEG}^{22}$.

O etanol tem uma afinidade muito maior pelo sítio ativo da enzima álcool desidrogenase do que o DEG, portanto, inibe competitivamente o metabolismo. 0 tratamento precoce é de extrema importância, pois a inibição do ADH não impede a toxicidade causada pelas toxinas já metabolizadas ${ }^{22}$.

O tratamento com administração do etanol endovenoso, ou oral, foi desenvolvido após a observação de que a ingestão concomitante de bebidas alcoólicas desacelera o metabolismo dos álcoois por competição com o substrato do $\mathrm{ADH}$. Torna-se essencial monitorar a glicemia do paciente durante toda infusão devido à hipoglicemia que 0 etanol pode causar. 0 fomepizol (4-metilpirazol) também é um potente inibidor competitivo do $\mathrm{ADH}$ com afinidade mais de 8000 vezes superior à do etanol e é considerada a droga de referência devido à sua elevada eficácia, farmacocinética previsível, melhor perfil de segurança, regime de administração simples e padronizado, menor necessidade de monitorização e maior tempo de ação. Além disso, ao contrário do etanol, não intoxica, não deprime o SNC e não causa hipoglicemia. Entretanto, o fomepizol não é comercializado no Brasili ${ }^{23}$.

Intoxicações potencialmente graves devem ser tratadas com hemodiálise que é efetiva em remover DEG e seus metabólitos diminuindo a duração da intoxicação, além de corrigir as alterações metabólicas. A hemodiálise deve ser contínua até a acidose metabólica, o ânion gap e gap osmolar se normalizarem e os sinais sistêmicos de toxicidade desaparecerem ${ }^{22}$.

\section{Legislação no Brasil}

No Brasil não existe legislação específica para trocadores de calor. Entretanto, é de responsabilidade da indústria garantir a segurança dos produtos fabricados. Nos Estados Unidos, por exemplo, existe uma lista específica de químicos permitidos para esta finalidade nos Códigos Federais de Regulamentações (CRF 21 178.3570). Além disso, o FDA tem um guia chamado "Heat Exchangers to Avoid Contamination" - Como evitar contaminação por trocadores de calor (tradução própria). A NSF International - The Public Health and Safety Organization, uma empresa também americana, tem um processo para registro de fluidos de trocadores de calor que são divididos em duas categorias: $\mathrm{HT} 1 \mathrm{e}$ $\mathrm{HT} 2$, sendo HT1 fluidos que terão contatos com alimentos, e HT2 fluidos sem contato com alimento. Vale ressaltar que o DEG não consta como HT1, não sendo permitido, por exemplo, para ser utilizado em serpentinas embebidas em alimento ou bebidas ${ }^{25}$.

\section{CONSIDERAÇÕES FINAIS}

Várias referências encontradas citam o DEG como contaminante que não possui nenhuma razão para estar presente em alimentos e bebidas. Como descrito no presente estudo, o DEG é um agente tóxico e, devido à sua biotransformação, seus metabólitos possuem elevada toxicidade. Apontando os casos de intoxicações desde 1937, observou-se que ocorreram falsificações, adulterações e contaminações de cunho farmacêutico ou alimentício, resultando em diversas mortes. No Brasil não aconteceu diferente. Os primeiros casos foram notificados ao final do ano de 2019. A Secretaria de Saúde de Minas Gerais, a PCMG e o Ministério da Saúde desencadearam uma investigação conjunta e após meses de trabalho em busca de esclarecimentos, foi constatada a presença de DEG em diversos lotes de uma famosa cervejaria artesanal em Minas Gerais. As principais falhas que causaram a contaminação foram: descumprimento do disposto no manual de instruções do tanque que recomendava o uso de etanol como anticongelante; tanque fermentador com defeito: furo na solda que ocasionou a contaminação; falta de manutenção dos equipamentos e falha na implementação de sistema de controle para redução de riscos. Existem pontos que merecem atenção quando 0 assunto é controle de qualidade: o maior erro está em avaliar as normas e procedimentos apenas na etapa final, e isso pode custar caro. A falta de qualidade é apenas uma consequência de um ato de descuido, e isso gera custos, sendo o mais grave deles a perda de vidas. 


\section{REFERÊNCIAS}

1. Devoti E, Marta E, Belotti E, Bregoli L, Liut F, Maiorca P, et al. Diethylene glycol poisoning from transcutaneous absorption. Am J Kidney Dis. 2015;65:603-606.

2. Fink JK. Oil field chemicals. 1 ed. Burlington MA, USA: Gulf Professional Publishing; 2003.

3. Medeiros PSG. Desenvolvimento e caracterização de soluções ternárias água-glicerol- propilenoglicol como fluido refrigerante secundário [Dissertação de Mestrado]. Rio Grande do Norte. Universidade Federal do Rio Grande do Norte; 2012.

4. Landry GM, Martin S, McMartin KE. Diglycolic acid is the nephrotoxic metabolite in diethylene glycol poisoning inducing necrosis in human proximal tubule cells in vitro. Toxicol Sci. 2011;124(1):35-44. 5. Landry GM, Dunning CL, Conrad T, Hitt MJ, McMartin KE. Diglycolic acid inhibits succinate dehydrogenase activity in human proximal tubule cells leading to mitochondrial dysfunction and cell death. Toxicol Lett. 2013;221(3):176-184.

6. Alkahtani S, Sammons H, Choonara I. Epidemics of acute renal failure in children (diethylene glycol toxicity). Arch Dis Child. 2010;95:1062-1064.

7. Schier JG, Rubin CS, Miller D, Barr D, McGeehin MA. Medication- associated diethylene glycol mass poisoning: a review and discussion on the origin of contamination. J Public Health Policy. 2009;30(2):127-143.

8. Ballentine C. Sulfanilamide Disaster. FDA Consumer magazine [Internet] 1981 [acesso em 19 de abr 2021]. Disponível em: https:// www.fda.gov/files/about\%20fda/published/The-Sulfanilamide-Disaster.pdf.

9. Bowie MD, Mckenzie D. Diethylene glycol poisoning in children. S Afr Med J. 1972;46: 931-934.

10. Cantarell MC, Fort J, Camps J, Sans M, Piera L. Acute intoxication due to topical application of diethylene glycol. Ann Intern Med. 1987;106(3):478.

11. Schep L, Slaughter RJ, Temple WA, Beasley DMG. Diethylene glycol poisoning. Clin Toxicol. 2009;47(6):524-535.

12. Ferrari L, Giannuzzi L. Clinical parameters, postmortem analysis and estimation of lethal dose in victims of a massive intoxication with diethylene glycol. Forensic Sci Int. 2005;153(1): 45-51.

13. O'brien KL, Selanikio JD, Hecdivert C, Placide MF, Louis $\mathrm{M}$, Barr DB, et al. Epidemic of pediatric deaths from acute renal failure caused by diethylene glycol poisoning. JAMA 1998;279(15):1175-1180.
14-.Singh J, Dutta AK, Khare S, Dubey NK, Harit AK, Jain NK, et al. Diethylene glycol poisoning in Gurgaon, India, 1998. Bull World Health Organ. 2001;79(2):88-95.

15. Lin BL, Zhao ZX, Chong YT, Li JG, Zuo X, Tao Y, et al. Venous diethylene glycol poisoning in patients with preexisting severe liver disease in China. World J Gastroenterol. 2008;14(20):3236.

16. Peng XM, Huang MX, Gu L, Lin BL, Chen GH. Characteristics of patients with liver disease intravenously exposed to diethylene glycol in China 2006. Clin Toxicol. 2009;42(2):124-131.

17. Rentz ED, Lewis L, Mujica OJ, Barr DB, Schier JG, Weerasekera $\mathrm{G}$, et al. Outbreak of acute renal failure in panama in 2006: a case- control study. Bull World Health Organ. 2008;86(10):749-756. 18. Schier JG, Hunt DR, Perala A, McMartin KE, Bartels MJ, Lewis LS, et al. Characterizing concentrations of diethylene glycol and suspected metabolites in human serum, urine, and cerebrospinal fluid samples from the Panama DEG mass poisoning. Clin Toxicol (Phila). 2013; 51(10):923-929.

19. Relatório de ações: Cervejaria Backer. Ministério da Agricultura, Pecuária e Abastecimento. Brasília; 2020.

20. Akuse R, Eke FU, Ademola A, Fajolu IB, Gbelee HO, thejiahi $U$, et al. Diagnosing renal failure due to diethylene glycol in children in a resource-constrained setting. Pediatr Nephrol. 2012;27(6):1021-1028.

21. Thakur D. State lethargy amidst cough syrup poisoning. The Hindu [Internet] 2020 [acesso em 19 de abr 2021]. Disponível em: https://www.thehindu.com/opinion/op-ed/state-lethargy-amidstcough-syrup-poisoning/article30945444.ece.

22. Secretaria de Estado de Saúde de Minas Gerais. Protocolo de intoxicação exógena por dietilenoglicol (DEG); Belo Horizonte; 2020.

23. Sociedade Brasileira de Nefrologia. Nota técnica e orientações da Sociedade Brasileira de Nefrologia e seu departamento de injúria renal aguda sobre intoxicação por dietilenoglicol. São Paulo; 2020

24. Brophy PD, Tenenbein M, Gardner J, Bunchman TE, Smoyer WE. Childhood diethylene glycol poisoning treated with alcohol dehydrogenase inhibitor fomepizole and hemodialysis. Am J Kidney Dis. 2000;35(5):958-62.

25. Dias J. O uso do dietilenoglicol em trocadores de calor na indústria de alimentos e bebidas. Food Safety Brazil [Internet] 2020 [acesso em 20 de abr 2021]. Disponível em: https://foodsafetybrazil.org/dietilenoglicol-em-trocadores-de-calor-na-industria-de-alimentos-e-bebidas. 